\title{
Asking and telling: An assessment of the feasibility of screening children for sexual violence in Kenyan school and health facility contexts
}

Chi-Chi Undie

Population Council

Margaret Mak'anyengo

Follow this and additional works at: https://knowledgecommons.popcouncil.org/departments_sbsr-rh

Part of the International Public Health Commons, and the Social and Behavioral Sciences Commons How does access to this work benefit you? Let us know!

\section{Recommended Citation}

Undie, Chi-Chi and Margaret Mak'anyengo. 2020. "Asking and telling: An assessment of the feasibility of screening children for sexual violence in Kenyan school and health facility contexts." Nairobi: Population Council. 


\section{Asking and Telling \\ An Assessment of the Feasibility of Screening Children for Sexual Violence in Kenyan School and Health Facility Contexts}

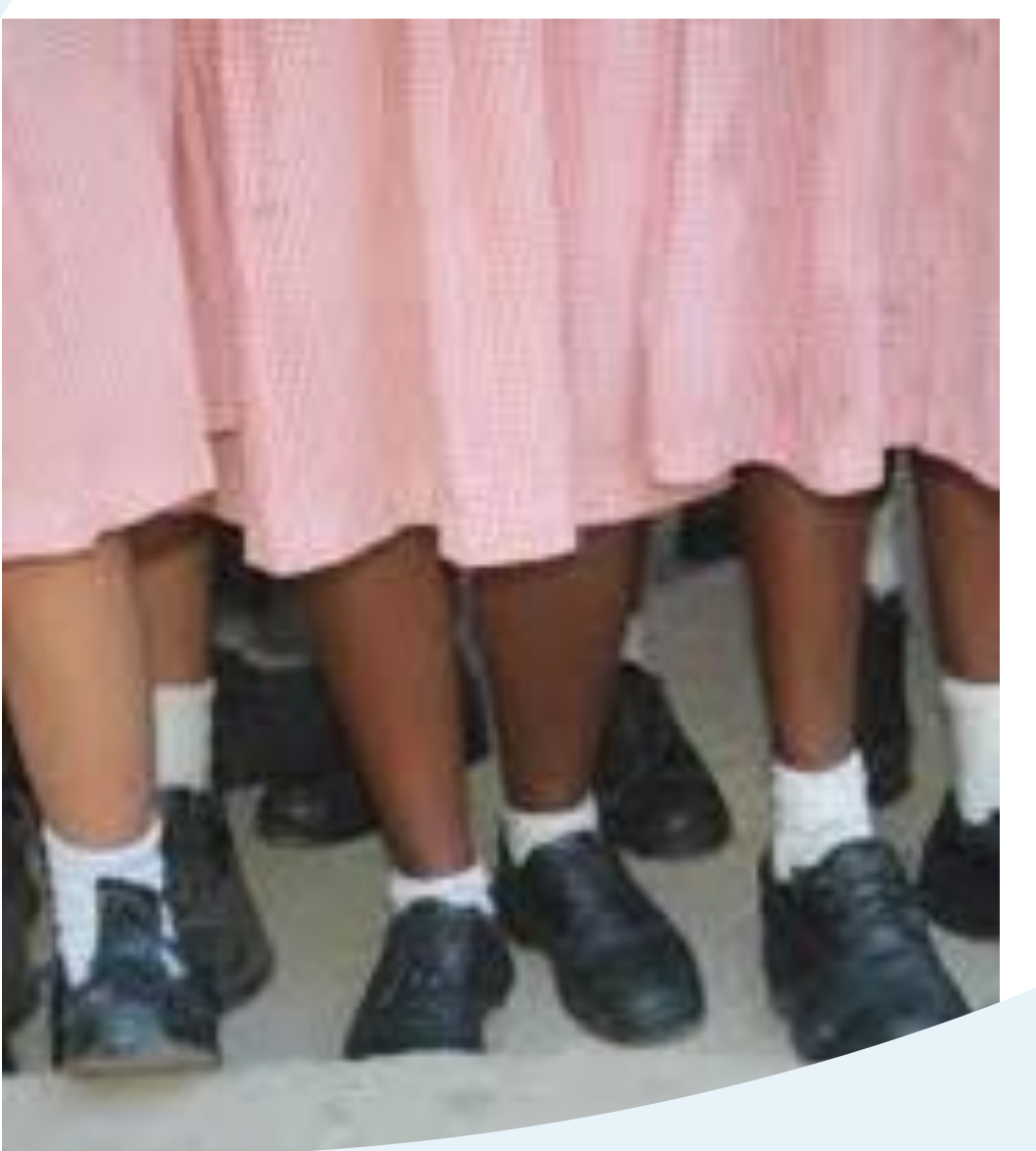

Chi-Chi Undie Population Council

Margaret Mak'anyengo

Kenyatta National Hospital

2020 


\section{POPULATION COUNCIL \\ Ideas. Evidence. Impact.}

The Population Council confronts critical health and development issues-from stopping the spread of HIV to improving reproductive health and ensuring that young people lead full and productive lives. Through biomedical, social science, and public health research in 50 countries, we work with partners to deliver solutions that lead to more effective policies, programs, and technologies that improve lives around the world. Established in 1952 and headquartered in New York, the Council is a nongovernmental, non-profit organization governed by an international board of trustees.

Avenue 5, 3rd Floor, Rose Avenue

P.0 17634-00500

Nairobi

Kenya

Tel: +254202713480

www.popcouncil.org

Suggested citation: Chi-Chi Undie, Margaret Mak'anyengo. 2020. Asking and Telling: An Assessment of the Feasibility of Screening Children for Sexual Violence in Kenyan School and Health Facility Contexts. Nairobi: Population Council

Cover photo: Courtesy of The Star, Kenya

(c)2020 The Population Council, Inc. 


\section{TABLE OF CONTENTS}

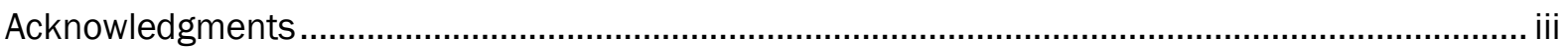

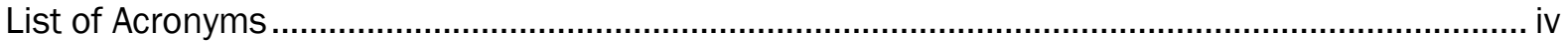

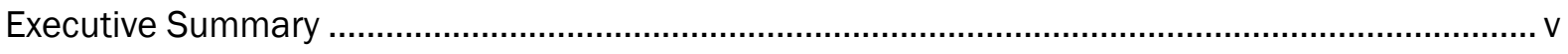

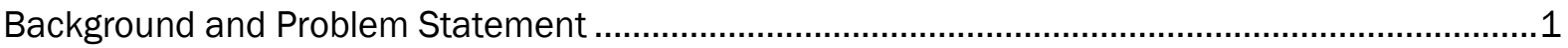

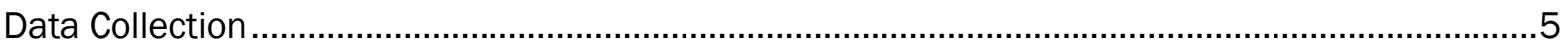

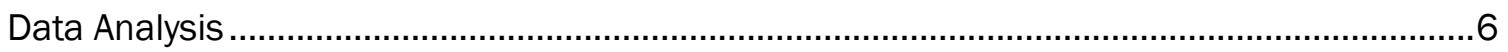

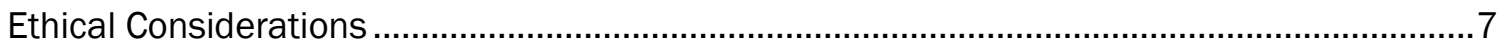

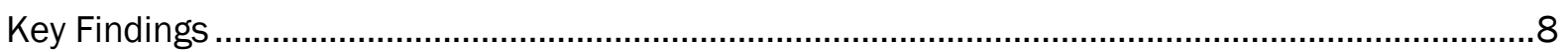

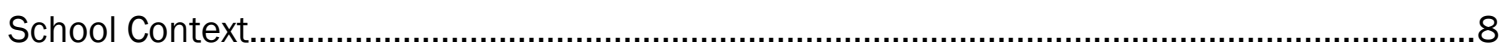

Expressed Interest and Intention to Use the Screening Intervention among Parents .........8

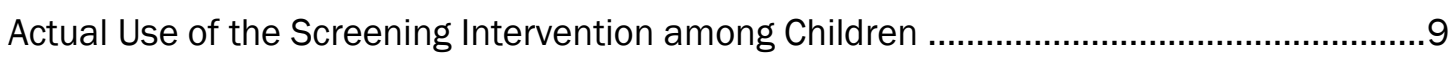

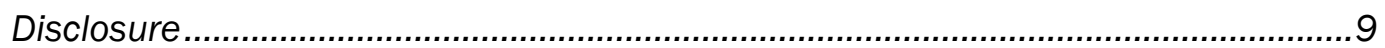

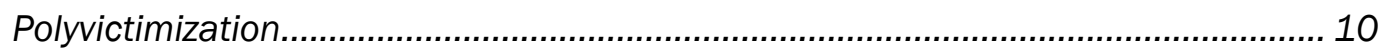

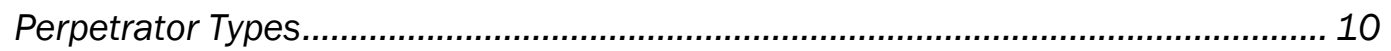

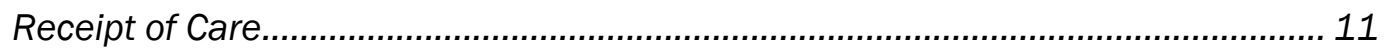

Perceived Appropriateness of the Intervention among School Personnel.......................... 12

Perceived Demand for the Intervention in the Wider Community ...................................... 13

Satisfaction with the Screening Intervention among Children........................................... 13

Perceived Positive Effects on Organization ...................................................................... 14

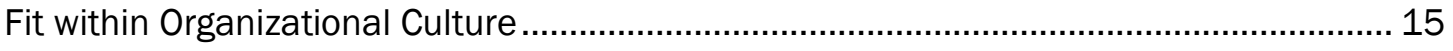

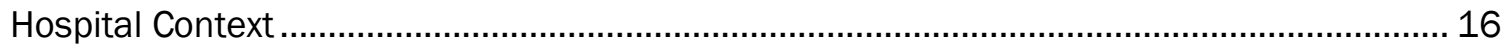

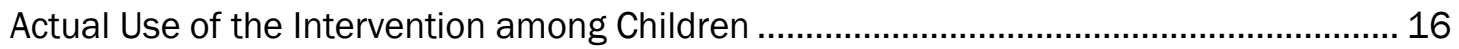

Perceived Appropriateness of the Intervention among Parents and Hospital Personnel . 16

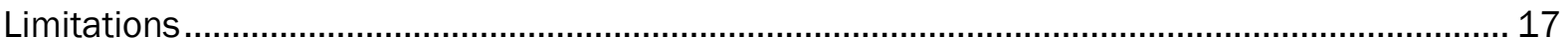

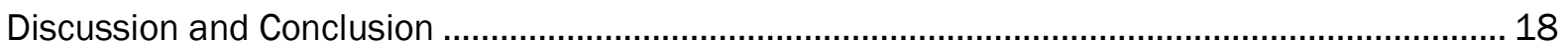

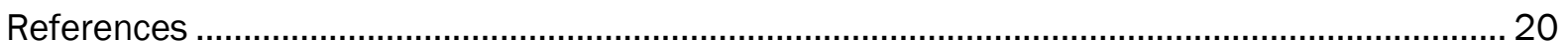

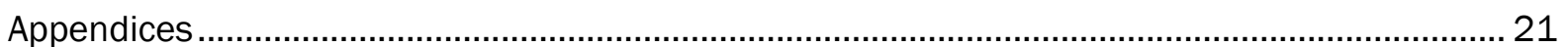

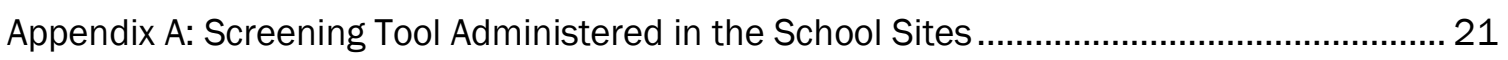

Appendix B: Screening Tool Administered in the Hospital Site ............................................... 25

Appendix C: Parent Permission Form (for parents participating in school-based parent dialogues) 


\section{ACKNOWLEDGMENTS}

We gratefully acknowledge financial support from the Regional Team for Sexual and Reproductive Health and Rights, Embassy of Sweden, Lusaka, Zambia, which made this study possible.

We are also deeply appreciative of the important contributions made by many stakeholders to this study: the children, parents, and overall staff at the two school sites and Kenyatta National Hospital; the Kenyatta National Hospital-based psychologists who provided support for the intervention, including: Theresa Wambui (deceased), Gertrude Kinyua, and Getter Wasilwa; the school-based psychologists: Hellen Murugi, Jane Musia, Khadiala Khamasi, and Nancy Buba; Wanjala Wafula (deceased) and Tom Saria, who supported the male engagement aspects of the intervention; and Irene Namai, who conducted all the study interviews.

We also owe a debt of gratitude to Population Council colleagues, Joyce Ombeva, for administrative support, and Janet Munyasya, for designing and formatting the report. 


\section{LIST OF ACRONYMS}

GBVRC Gender-Based Violence Recovery Centre

KNH Kenyatta National Hospital

SGBV Sexual and Gender-Based Violence

SV

Sexual Violence

SVAC

Sexual Violence Against Children 


\section{EXECUTIVE SUMMARY}

Although sexual violence against children (SVAC) is increasingly acknowledged as prevalent in Kenya, documented and tested interventions for proactively identifying child survivors and providing them with care are currently non-existent. Proactive identification of sexual violence (SV) survivors through screening mechanisms has been shown to be not only highly acceptable among Kenyan adults, but to also promote detection of adult survivors and their use of SV services. Such screening could potentially identify and respond to child survivors, ages 11 and older, as well, but studies are needed to verify this proposition.

This study aimed to determine the feasibility of screening children for SV in both school and health facility settings, and of providing child survivors identified through this process with access to care. The four-component intervention, implemented from January through April 2017, involved parent dialogues; student sensitization; provider training to administer a child-friendly screening tool and respond to child survivors; and SV screening, paired with SV service provision. The screening intervention was implemented in the Casualty Department of Kenyatta National Hospital in Nairobi, in addition to two Nairobi primary schools.

In the two schools, students in Classes 6 to 8 (ranging from 10 to 17 years of age) were screened, while at the hospital, children ages 11 to 17 were screened. Parents of students eligible for screening were invited to participate in dialogues at the schools before the screening intervention commenced in these sites.

The intervention was evaluated using a mixed methods study design, with quantitative data collected primarily via the screening tool, and qualitative data generated via fieldnotes recorded during interactions with child survivors and parents, group interviews with hospital personnel who supported the intervention, and semi-structured individual interviews with school personnel who supported the intervention.

In the school and hospital sites combined, the study results aligned with 8 out of 8 feasibility outcomes described by Bowen et al. (2009). Further information on these feasibility outcomes and the results associated with them are summarized separately for the school and hospital sites below:

\section{School Site Findings}

Screening for SVAC in schools was found to be feasible, in accordance with seven specific outcomes:

\section{Expressed Interest or Intention to Use the Screening Intervention among Parents}

- A large proportion (61\%) of parents gave permission for their children to be privately screened for SVAC at school.

- Parents from non-participating schools attended the parent dialogues despite their not being targeted by the intervention. Parents from participating schools contended that the intervention should have been offered to all children in the schools, rather than just those in Classes 6 to 8 . During parent dialogues, some parents also expressed personal need for counseling, as they suspected their children had experienced SV - before the intervention's actual screening component commenced.

\section{Actual Use of the Screening Intervention among Children}

- Almost all children (96\%) who received parental permission to be screened for SVAC were also independently willing to participate in SVAC screening. 
- About half (49\%) of children screened indicated that they had ever experienced some form of SV.

- Most children who disclosed ever having experienced SV obtained care due to this intervention (75\%).

\section{Perceived Appropriateness of the Intervention among School Personnel}

Most school staff called for the expansion of the screening intervention to additional age groups and locations. Teachers believed they were not suited to conduct the screening intervention themselves, and found it more appropriate and helpful for psychologists or counselors to fulfill this role.

\section{Perceived Demand for the Screening Intervention in the Wider Community}

The implementation process in schools appeared to have a ripple effect on the wider community, compelling children, parents, and school personnel to inform others not directly linked to the intervention about the latter, and to link them to intervention services.

\section{Satisfaction with the Screening Intervention among Children}

Children in schools expressed high levels of satisfaction with the screening intervention, and were particularly satisfied with its effects on parent-child communication, which facilitated their disclosure and discussion of SV experiences with their parents.

\section{Perceived Positive Effects of the Screening Intervention on Organization}

School staff believed the intervention enhanced their students' confidence in academic pursuits, and in communicating with their teachers.

\section{Fit of the Screening Intervention within Organizational Culture}

School personnel suggested that their time constraints posed modest challenges for the screening intervention.

\section{Hospital Site Findings}

Within the hospital, SVAC screening was found to be feasible, in accordance with three outcomes:

\section{Perceived Appropriateness of the Screening Intervention among Parents}

Parent dialogues did not occur at the hospital site, but all parents in the hospital setting gave permission for their children to be privately screened for SV.

\section{Actual Use of the Screening Intervention among Children}

- All children who received parental permission to be screened for SV at the hospital were also independently willing to undergo such screening.

- Ten percent of children screened indicated they had ever experienced some form of SV.

- Most children in the hospital site who disclosed having ever experienced SV, obtained care.

\section{Perceived Appropriateness of the Intervention among Hospital Personnel}

Hospital personnel called for the scale-up of the screening intervention to other departments/clinics within the hospital (and within the education sector) to ensure broader reach. They also emphasized the appropriateness of routinizing the screening process to foster greater disclosure among children.

Together, these findings indicate that screening for SVAC is feasible in both school and health facility settings, and that such screening holds potential for expanding child survivors' access to care. 


\section{BACKGROUND AND PROBLEM STATEMENT}

This study aimed to assess the feasibility of screening for sexual violence against children (SVAC) within school and health facility settings in Nairobi, Kenya. In health facility contexts, 'screening' is defined as "the standardized assessment of patients, regardless of their reasons for seeking medical attention" (MacMillan et al. 2009). This definition was applied to school settings as well in this study.

Screening for sexual violence (SV) has been shown not only to be highly acceptable in Kenya (Undie et al. 2012), but also to promote detection of adult survivors and their use of SV services (Undie et al. 2013, 2016). Little is known, however, about how to effectively screen children for SV in Kenya, where SVAC is increasingly acknowledged as a problem. Evidence indicates that 76 percent to 80 percent of children in the country experience at least one type of violence (sexual, physical, or emotional) prior to age 18 (MLSP Kenya 2019). SV is at particularly worrisome levels among children in Kenya: 16 percent of females and 6 percent of males ages 18 to 24 report experiencing this form of violence during their childhood years (i.e., before the age of 18). Of these, nearly 60 percent of girls did not tell anyone (ibid.; among boys, the estimate was unreliable). Furthermore, although 35 percent of girls and 34 percent of boys who had experienced SV knew where they could seek services, only 11 percent of girls and 3 percent of boys received services for their SV incidents.

Childhood experiences of SV often occur for the first time at school, according to the 2019 Violence Against Children in Kenya national survey (MLSP Kenya 2019). For nearly 20 percent of girls ages 18 to 24 who experienced SV in childhood, and 22 percent of girls who specifically experienced pressured or physically forced sex in childhood, their initial assaults occurred in a school setting, making schools critical contexts for addressing children's experiences of SV.

While SV is a public health concern in and of itself, it also places children and adolescents at greater risk for pregnancy and sexually transmitted infections, including HIV. In a nationally representative survey of 1,306 females in Kenya ages 13 to 24, 30 percent of those who reported experiencing coercive sex before the age of 18 became pregnant as a result (ibid.). Those who reported experiencing SV in childhood were significantly more likely to report feelings of anxiety, depression, suicidal thoughts, and fair or poor health than their female peers who did not experience SV.

Despite the undeniable problems that SV poses for children and adolescents in Kenya, and the potential for screening's early detection of it-the World Health Organization (WHO, 2016)) has endorsed screening, coupled with response interventions, as a strategy for improving child survivors' access to services -systematic, documented SV screening interventions for children are currently nonexistent in Kenya. Existing SV interventions for children in this context were typically designed and implemented with adult women in mind, and eventually offered to children out of sheer demand (Undie, Mullick, Askew 2013). Yet, children require tailored programming to ensure that their specific needs are properly met. For example, children's abilities to respond to SV might be hampered, as they are usually less aware of, or unable to independently seek, services or support (ibid.). Screening, coupled with referral, could potentially help overcome these barriers.

Qualitative findings from Nairobi (Population Council, 2016) provide contextual information to help guide SVAC screening in urban poor schools and health facilities, concluding that any screening intervention for SVAC in such settings must: 1) be specifically developed to address continuous trauma in children, 2) inform parents of the consequences of SV and engage them in supporting affected children, and 3) find alternatives to the reliance upon teachers to screen for such violence. The intervention described and evaluated in this report incorporated these recommendations into its design. 


\section{STUDY AIM AND DESIGN}

\section{Aim}

This study aimed to determine the feasibility of screening children in school and health facility settings for SV, and of linking child survivors identified through this process to care. Two specific dimensions of feasibility, as outlined by Bowen et al. (2009), were evaluated:

Acceptability-the extent to which the screening intervention is judged as suitable, satisfying, or attractive by intervention recipients, and

Demand-the extent to which screening is likely to be used-i.e. how much demand likely exists?

These dimensions are broken down further into the specific feasibility outcomes investigated in this study (Table 1):

\begin{tabular}{|c|c|c|}
\hline \multicolumn{3}{|c|}{ Table 1: Key areas of focus for feasibility studies and possible outcomes } \\
\hline Area of focus & The feasibility study asks ... & Sample outcomes of interest \\
\hline Acceptability & $\begin{array}{l}\text { To what extent is a new idea, program, } \\
\text { process, or measure judged as } \\
\text { suitable, satisfying, or attractive to } \\
\text { program deliverers? to program } \\
\text { recipients? }\end{array}$ & $\begin{array}{l}\text { - Satisfaction } \\
\text { - Intent to continue use } \\
\text { - Perceived appropriateness } \\
\text { - Fit within organizational culture }\end{array}$ \\
\hline Demand & $\begin{array}{l}\text { To what extent is a new idea, program, } \\
\text { process, or measure likely to be used } \\
\text { (i.e., how much demand likely exists)? }\end{array}$ & $\begin{array}{l}\text { - Perceived positive or negative effects } \\
\text { on organization } \\
\text { - Actual use } \\
\text { - Expressed interest or intention to use } \\
\text { - Perceived demand }\end{array}$ \\
\hline
\end{tabular}

Adapted from Bowen et al., 2009

\section{Design}

The study used a mixed-methods design, drawing specifically on a 'concurrent triangulation' strategy (Creswell et al., 2003), which involves the concurrent collection of quantitative and qualitative data, with the subsequent merging of both data sets into one overall interpretation. While quantitative data alone might have sufficed for determining the feasibility of the screening intervention, qualitative data were deemed equally important for providing a deeper understanding of the perceptions, feelings, and experiences of screened children, their parents, and school and hospital personnel around this sensitive intervention, and particularly for 'giving voice' to children, who are often omitted from SV studies.

The qualitative data collection drew on participant observations by trained psychologists who carried out the screening intervention. Fieldnotes ('rich, detailed descriptions, including the context within which the observations were made' [Patton, 2003, p. 2]) were the primary means of data capture from participant observations, and were extensively recorded in this study. In addition, qualitative interviews were carried out with school and hospital personnel engaged in the intervention.

Kenyatta National Hospital (KNH) and two primary schools located in relatively close proximity to this hospital served as the study sites. KNH is a tertiary, government teaching and referral health facility, and also happens to be the oldest and largest hospital in the country. It is home to the Gender-Based Violence Recovery Centre (GBVRC), a leading government one-stop response center for sexual and gender-based violence (SGBV) in Kenya, offering a full range of care and multi-sectoral support for SGBV survivors either directly, or through referrals within and outside $\mathrm{KNH}$. 
The GBVRC began programming at the two primary schools a few years before this study, creating SV awareness among students. Although the two schools are not located within informal settlements, each has a large population of students from such settings.

\section{Screening Tool Development}

To support the intervention and elicit SV information, a child-friendly screening tool (see Appendix) was collaboratively developed by the Population Council and KNH. The tool focused on children's lifetime and current experiences of SV, types of SV experienced, the timing of SV experiences, perpetrator types, and whether children with SV experiences were interested in professional help - and if so, whether they would like to have their female parent involved in their care. Selected questions, such as type of SV experienced, were designed to be open-ended, allowing children to describe their experiences in their own words, as children are unlikely to assign technical terms to these experiences. The following definition of SV was employed: "non-consensual completed or attempted sexual contact and acts of a sexual nature not involving contact (such as voyeurism or sexual harassment)" (WHO 2020).

Face validity and structural validity (Kaitelidou et al. 2019) were established for the screening tool in two stages. A team of three SVAC experts from KNH's GBVRC and Pediatric Department, and the Population Council established face validity by drafting the screening questions in accordance with the screening tool's goals. Structural validity was assured by pilot-testing the draft version of the screening tool at the study sites for three days, through trained psychologists. Subsequent debriefing meetings with the psychologists identified screening question comprehension or sensitivity issues, as well as any procedural problems. This process resulted in the development of the final version of the screening tool.

\section{Intervention Description}

The intervention comprised four components: Parent Dialogues, Student Sensitization, Provider Training, and Screening for SVAC, coupled with SV service provision.

\section{Parent Dialogues (January Through April 2017)}

In the two participating primary schools, dialogues were considered critical for gaining parents' buy-in for having their children screened and connected to services, in their absence, for an issue as sensitive as SV. Two dialogues with parents were held at each primary school. Parents of all students in Classes 6 to 8 (typically 12 to 14 years of age) were invited by the schools to participate in the one-day dialogues, which took place on Saturdays. These parent dialogues involved guided, interactive exercises (e.g,, scenario-building and discussion prompts) conducted by the Population Council and $\mathrm{KNH}$ to stimulate discussion around SVAC and other related topics in these communities, such as the negative consequences of such abuse, barriers to child reporting, parental barriers to seeking care for affected children, and school-based screening as a possible solution.

The first set of dialogue meetings were also used to as a platform for administering written consent to willing parents for their children to participate in the screening exercise, using parent permission forms (see Appendix), and to receive school-based counseling and/or accompanied referrals to the GBVRC, depending on the nature of SVAC disclosed. Dialogue facilitators clarified to parents that there was no expectation from the school or others that all students should participate. Rather, the participation of students was voluntary, a decision to do so could be reversed, and a decision not to participate would hold no negative repercussions for students or their parents.

The first set of parent dialogues attracted female parents and caregivers almost exclusively. To foster greater participation by male parents and caregivers, the second set of parent dialogues were designated "Fathers' Days," and the schools sent children home with invitations indicating that the meeting would be a 'goat-eating'-a traditional Kenyan means of convening men to socialize and 
discuss issues over a meal of roasted goat meat. This strategy proved highly successful in attracting and engaging men. Participants were served lunch during each dialogue (prepared on school premises), and at the end of each meeting, each parent was sent home with a packet of flour and sugar.

\section{Student Sensitization (January 2017)}

Primary school students were provided information about the planned intervention by GBVRC psychologists during routine weekly student assemblies, over the course of four weeks. As these sessions were during regular school assemblies, all children in the school received the information. During the assemblies, GBVRC psychologists defined sexual abuse and informed students that their schools were taking measures to make it easier for students to receive care if or when such abuse occurred, in addition to providing details of services that would be available at the schools.

\section{Provider Training (January 2017)}

Health care providers involved in the study included four GBVRC psychologists assigned to the schools (two per school) during the study period, one GBVRC psychologist already assigned to the Casualty Department at KNH, and all available GBVRC psychosocial support staff. These providers received three days of training in narrative therapy for child survivors and their parents or caregivers, drawing on the 'Tree of Life' psycho-social support tool. As narrative therapy involves the 're-authoring' or 're-storying' of conversations, it makes a distinction between people and their problems, supporting survivors' abatement of the influence of violence in their lives. The narrative therapy training for providers was facilitated by the Regional Psychosocial Support Initiative, and was grounded in psychosocial response approaches developed by the same institution.

The psychologists who actually screened children for SV in schools and $\mathrm{KNH}(n=5)$ received an additional one-day training focused on using the screening tool with children, recording screening results and fieldnotes based on screening interactions, managing referrals for child survivors, and serving as advocates who worked to ensure abused children accessed requisite services.

\section{Screening for SVAC and Service Provision (January to April 2017)}

\section{Hospital Site}

At $\mathrm{KNH}$, screening occurred only in the Casualty Department. The psychologist stationed in this department was in charge of screening children who presented for care. To be eligible for screening, a child had to be: 1 ) accompanied solely by a female parent or caregiver, or had to have presented for care alone, 2) of ages 11 to 17,3 ) cleared by a pediatric nurse as presenting with a mild (as opposed to severe) illness, and 4) permitted by the female parent or caregiver (if applicable) to be asked screening questions privately. Children who presented for care with a male parent or caregiver were ineligible for screening, to lessen the likelihood of negative consequences for minors whose abusers are their male parents or caregivers.

The psychologist held brief, private sessions with each the female parent or caregiver and child presenting at the Casualty Department during the study period, explaining that the prevalence of SVAC had prompted the Department to routinely ask each child a few questions to assess their situation and provide on-site referrals for SV care, if necessary. Parents and caregivers willing for their children to be screened were asked to leave the room a few minutes.

Children disclosing SV and their parents or caregivers then received a referral from the psychologist to the GBVRC for comprehensive care, along with the explanation that services were available not just for child survivors, but for caregivers as well, to better cope with the complexities of SVAC. 


\section{School Sites}

At the two primary school sites, screening was facilitated by a similar screening tool, with variations solely to the preamble and not the actual screening questions (see Appendix). GBVRC psychologists based at the schools conducted the screening exercise during recess, free periods, and after-school activities. All students in Classes 6 to 8 with parental permission were invited to participate in the screening exercise.

The psychologists maintained a register of eligible students, and with the assistance of guidance and counseling teachers in each school, invited students listed on the register individually for screening. Students were then screened in a private room designated for this purpose. Each eligible student was screened twice during the intervention period, if SV was not disclosed the first time.

Children disclosing SV were asked if they would like to talk to someone further and get help, along with their female parent or caregiver. Those willing received school-based counseling by the screening psychologist and/or an accompanied referral to the GBVRC, depending on the nature and severity of the violence disclosed, and the child survivor's comfortability with involving their female parent or caregiver.

In both the school and hospital settings, psychologists were trained to use aids along with the screening tool. They were supplied with male and female dolls for children to use to demonstrate the kind of SV they had experienced, if preferred. Children also had the option of writing "yes" or "no" responses to the questions posed (or of holding up a card), rather than responding verbally, if they preferred.

\section{Data Collection}

In accordance with a mixed methods design, both quantitative and qualitative data were collected.

\section{Quantitative Data}

Permission slips were offered to all parents who attended the first set of parent dialogues, for indication of their permission (or refusal) for their child's participation in SV screening at school, and potential accompaniment to the GBVRC, if necessary. Children whose parents gave their permission for this process were also asked if they would like to participate in the screening intervention. A register of those who assented was maintained by the screening psychologists. The parent permission and child assent information was collated as part of the quantitative data set.

Additionally, the psychologists documented statistics based on the screening questions found in the screening tool, including the total number of children disclosing lifetime and current experience of SV, types of SV disclosed, perpetrator types, and the number of child survivors interested in receiving help. Service statistics related to referral receipt and completion were also collated.

\section{Qualitative Data}

\section{Fieldnotes}

Psychologists recorded descriptive fieldnotes by hand during screening sessions with each child disclosing SV, including verbatim comments by the children, descriptions of non-verbal behavior, and other observations. A total of 222 fieldnotes were compiled (i.e., one set of notes per child disclosing SV). To capture the 'voices' of parents as well, psychologists also documented fieldnotes based on the four parent dialogues and other interactions with parents.

Fieldnote documentation entailed making initial rough notes or 'jottings' during and immediately after screening and parent dialogues (Sanjek 1990, Emerson et al. 1995). These notes were then expanded 
and written up in full as soon as possible the same day, by including what Emerson et al. (1995, p. 101) refer to as asides: "brief, reflective bits of analytic writing that succinctly clarify, explain, interpret or raise questions about some specific happening or process described in a fieldnote."

\section{Group Interviews}

Three group interviews were conducted with a total of eight providers: one with school-based psychologists carrying out the screenings, a second with hospital-based psychologists screening Casualty patients at $\mathrm{KNH}$, and a third with GBVRC providers responding to survivors identified through the screening process. In group interviews, "two or more people are interviewed at once by one or more interviewers" (Myers \& Newman 2007, p.4). Each group interview with providers involved two to four participants.

\section{Semi-Structured Interviews}

Nine semi-structured interviews were carried out with primary school personnel, including school administrators and teachers.

All group and individual interviews were facilitated by field guides designed to elucidate domains that related to the feasibility of the intervention in schools and health facilities.

The various forms of qualitative data were typed up and de-identified prior to analysis.

\section{Data Analysis}

\section{Quantitative Data}

The screening tool encouraged children to describe the type of SV they experienced, in their own words. Each description was categorized under the technical term for the SV type, and then quantified. Other dimensions of the screening tool were purely quantitative.

Analysis of quantitative screening tool data from all sites entailed entering these data into an Excel spreadsheet by screening tool question and generating descriptive statistics for each variable. Quantitative data generated from the parent permission slips (e.g., number of parents consenting for their children to participate in the intervention versus those who did not) were analyzed manually. Data generated from the permission slips and screening tool were then categorized according to the feasibility dimensions of 'acceptability' and 'demand.'

The denominators for analysis of the quantitative data included the total number of parents eligible to participate in the dialogues (i.e., that had a child in Classes 6 to 8 and had been invited by the school), and the total number of parents who returned their permission slips, regardless of response.

\section{Qualitative Data}

The qualitative data were used to confirm and corroborate the quantitative findings. The analysis of qualitative data drew on content analysis techniques. For the fieldnotes specifically, the screening tool topics served as the initial thematic codes for this analysis, as far as possible. Fieldnote transcripts were analyzed according to these codes through repeated readings. The analysis involved identifying narratives that were consistent with the quantitative data categories at 'descriptive' and 'conceptual' levels (Shallcross et al., 2019): fieldnote excerpts that could describe the quantitative results in more detail, or that embodied concepts highlighted by the quantitative data, were noted and categorized together as major themes. 
The next phase of analysis involved all qualitative data forms, and entailed coding these data according to their alignment with possible 'demand' and 'acceptability' outcomes, as identified by Bowen et al. (2009) and outlined in Table 1 below. The demand and acceptability outcomes outlined served as a priori codes, which were explored in further detail to gauge their alignment with any similar indicators found in the quantitative data set. Finally, analysis also took place as part of the process of writing up the results, as the very act of writing promoted the iterative process of clarifying, deepening, and strengthening the overall analytical process (Smith, Flowers, and Larkin, 2009).

\section{Ethical Considerations}

Ethical approval for the study was obtained from Population Council's Institutional Review Board as well as from the KNH-University of Nairobi Ethics and Research Committee. Permission to conduct the study in the schools was granted by the Nairobi County Education Office, Ministry of Education.

Both parental consent and child assent were required for children to be enrolled in the screening intervention. While children's 'voices' were considered critical for understanding their experiences, ethical considerations around interviewing potentially self-conscious and traumatized child survivors led us to rely on hand-recorded fieldnotes as qualitative data for child intervention participants, rather than on audio-recorded interviews.

In all study sites, screening occurred in rooms offering audio and visual privacy to ensure the confidentiality of the screening process.

To enhance participant comfort during the process, the screening tool contained prompts reminding children that they could hold up a card or write their answer as a response to "yes or no" questions, rather than answering verbally, and that they were free to refrain from answering any questions they did not want to, without any repercussions.

Additionally, the GBVRC was purposefully selected to implement this screening intervention, as it is a one-stop center for comprehensive care, equipped for a multi-sectoral SV response in accordance with Kenyan laws. Child survivors who required it therefore received accompanied referrals to the GBVRC for an appropriate and comprehensive response to their individual needs. 


\section{KEY FINDINGS}

Findings from the school sites are presented first, followed by results from the hospital context. In both cases, the feasibility outcomes of interest depicted in Table 1 serve as organizing themes.

\section{School Context}

\section{Expressed Interest and Intention to Use the Screening Intervention among Parents}

The vast majority of parents and caregivers were not only willing for their children to be screened for $\mathrm{SV}$, but to also permit psychologists conducting the screening to accompany their children to the GBVRC if they disclosed an experience of SV. The permission slips distributed at parent dialogues contained both caveats, and parents were only considered as permitting their children's participation if they acceded to both provisions. Of a total of 774 eligible parents and caregivers from the two participating schools combined, $583(75 \%)$ parents or caregivers returned permission slips during the parent dialogues, and of those, 81 percent $(n=473)$ gave permission for their children to be screened as well as escorted by the screening psychologist to the GBVRC for comprehensive care if necessary.

Demand for this kind of screening intervention was evident during the parent dialogues-even before the actual screening initiative began. Fieldnotes show that parents were eager for solutions to the predicament of SVAC. Some parents attended the dialogues even though they had not been invited, either because their children were not in Classes 6 to 8 at the participating schools, or because their children did not attend the participating schools at all. Some parents from non-participating schools attended the parent dialogues after hearing about them from others.

During the dialogues, several parents questioned the limited sampling of children in Classes 6 to 8 , contending that the intervention should have been offered to all children in the schools. Some parents also indicated that they were in need of personal counseling to be able to cope with their child's experience of SV:

"After the [parent dialogue] meeting, some parents took the initiative to ask what help can be given to their sexually abused children. Of the five parents who approached the...staff, only two were [eligible] for screening [i.e., were in the study range of classes 6 to 8]. One parent wanted counselling for her eight year old who was sexually abused when she was four. Two parents wanted counselling services for their children who do not attend the school. They wanted directions to [the GBVRC]. One parent wanted help for her daughter who is in Class 5 and is being sexually abused by her father. One wanted help for her daughter who is in Class 7 , who was sexually abused by the neighbor. All these parents talked to [GBVRC] staff on site and were given appointments."

Fieldnotes, parent dialogue, school A

" $\{$ At the end of the parent dialogue] some parents promised to come [back] to the school to talk to the psychologists concerning their children."

Fieldnotes, parent dialogue, school B

"A few parents who previously had children in School A, but had transferred their children to other schools due to incidents of suspected [sexual violence] also attended [the parent dialogue]. They wanted to know how to help their children. Some heard about the meeting from neighbors, while others had children in other classes and heard about the meeting from them." Fieldnotes, parent dialogue, school A

While only children in the participating schools in Classes 6 to 8 were eligible for screening, all children (regardless of age, grade, or school) brought to the attention of psychologists were offered services by the GBVRC. All parents or caregivers indicating the need for their own counseling sessions also received counseling at the school sites or the GBVRC, depending on their preference. 


\section{Actual Use of the Screening Intervention among Children}

Children were only eligible for screening if their parents gave their permission and if eligible children themselves indicated their willingness to participate. The vast majority of children were willing to be screened: 473 parents granted permission for their children to be screened, and 456 children (96\%) in both schools combined indicated their willingness to undergo SV screening. Of these, 62 percent were female and 38 percent were male.

\section{Disclosure}

Those screened were also willing to disclose SV experiences, demonstrating that SV affects a large proportion of school children: About half of those screened $(49 \%, n=222)$ indicated that they had ever experienced some form of SV. Both girls and boys were affected, with girls accounting for $59 \%$ of those reporting ever having experienced some form of SV, and boys accounting for $41 \%$.

As indicated in Table 2, genital touching was the principal type of SV reported by children, followed by attempted rape and forced viewing of pornography. Completed rape was reported by seven percent of those screened.

\begin{tabular}{|l|c|}
\hline \multicolumn{1}{|c|}{$\begin{array}{c}\text { Table 2: Proportion of children disclosing lifetime experience of sexual violence } \\
\text { by type of sexual violence }\end{array}$} & $\mathrm{n}=222$ \\
\hline & \\
\hline Type of Sexual Violence Disclosed & \\
\hline Genital touching & $64 \%$ \\
\hline Attempted rape & $22 \%$ \\
\hline Forced viewing of pornography & $12 \%$ \\
\hline Rape & $7 \%$ \\
\hline Attempted genital touching & $5 \%$ \\
\hline $\begin{array}{l}\text { Other (including forced touching of others' genitals, oral sex, } \\
\text { inappropriate (non-genital) touching) }\end{array}$ & $6 \%$ \\
\hline *Multiple responses allowed &
\end{tabular}

Of those who disclosed ever experiencing SV, 5 percent $(n=23)$ disclosed current SV: 74 percent girls and 26 percent boys.

In addition to "giving voice" to children's lived experiences of SV, these qualitative data provide further evidence of children's actual use of the screening intervention, demonstrating their willingness to respond to the screening questions. The detailed information provided by children's accounts points to children's comfortability with the screening tool and process:

"My mom sent me to throw away trash and this man called me [into his house], closed the door, and told me to lie down. I shouted, 'uuuiii, uuuiii,' but nobody heard me. I shouted again and he told me if I keep shouting, he'll kill me. He entered behind me and started 'doing bad manners,' which was very painful. I cried for help but the man [covered] my mouth. He later left me and told me to go without looking behind me or telling anybody about it..."

Fieldnotes, screening, 11 year old boy

"This neighbor...sent me to the shop to get him a box of matches. When I came back, he pulled me inside his house and started undressing me. I screamed and he said, 'Keep quiet, or l'll kill you.' I screamed louder and he got scared and left me alone. I didn't tell my mom because I thought she would beat me...I always feel sad and think if this man raped me, I would be pregnant..."

Fieldnotes, screening, 12 year old girl 
"When my dad was told about the incident, he said that it's nonsense, meaning he did not believe his brother raped me. It was so tough for my parents and they later separated. This is because mum was trying to protect me, but my dad was for his brother. Today, I feel good to have talked to you. Though I was treated [back then], I did not get a chance to talk to anyone about the issue. The incident makes me so sad when I remember it, and I cry alone because I have never talked to anyone about it."

Fieldnotes, screening, 11 year old girl

"He has been showing me his private parts as well. I was scared he may rape me and I told my mum. My mother asked him about it, and he was very rude. He met me on the road and told me, 'Continue telling your mum. One day, I will catch you'."

Fieldnotes, screening, 11 year old boy

\section{Polyvictimization}

A total of 34 children (15\%) who disclosed ever experiencing SV also disclosed experiencing more than one type of SV concurrently. These experiences of multiple sexual victimizations of different kinds are captured in Table 3 below. As the table indicates, genital touching is a highly prevalent form of SV that occurs in practically every instance of polyvictimization described by children.

\begin{tabular}{|l|c|}
\hline \multicolumn{1}{|c|}{$\begin{array}{c}\text { Table 3: Proportion of children disclosing lifetime experience of sexual violence } \\
\text { who had experienced more than one type of sexual violence concurrently }\end{array}$} \\
\hline & $\mathrm{n}=34$ \\
\hline Types of SV Experienced Concurrently & Number of children disclosing \\
\hline GT* + attempted rape & 14 \\
\hline GT + forced viewing of pornography & 6 \\
\hline Attempted GT + forced viewing of pornography & 3 \\
\hline GT + rape & 3 \\
\hline Attempted rape + rape & 2 \\
\hline GT + forced GT of others & 2 \\
\hline GT + forced oral sex & 2 \\
\hline GT + forced viewing of pornography + attempted rape & 1 \\
\hline Attempted GT + GT & 1 \\
\hline *GT Genital Touching
\end{tabular}

\section{Perpetrator Types}

Children's comfort with the screening intervention is evinced by their willingness to disclose the perpetrators of the SV they had experienced. The majority of perpetrators identified (51\%) were fellow students, as shown in Table 4. This pattern was similar among those disclosing that they were currently experiencing SV. Children's narratives provide insight into SV perpetrated by fellow students:

"Our school has some notorious boys who harass girls by touching our breasts, buttocks and others even want to put fingers in our private parts. When you tell them to stop, they tell us, 'Aah, you stop pretending, I know you like it and it makes you feel good.' This is really annoying and someone should find a way of stopping them before they start raping us."

Fieldnotes, screening, 13 year old girl, class 7

"This boy has been doing this thing for a very long time and I threatened to tell my teacher. He stopped, but recently, he has been asking me if we can have sex, and I said 'no'."

Fieldnotes, screening, 12 year old girl, class 6

"There is this girl who keeps on touching my private parts in my class. We have very naughty boys and girls who keep on touching other people's private parts. Like, there is one particular girl who keeps on touching my private parts and I don't know what to do with her."

Fieldnotes, screening, 13 year old boy, class 7 


\begin{tabular}{|l|c|}
\hline \multicolumn{2}{|c|}{$\begin{array}{c}\text { Table 4: Proportion of perpetrator types cited by children disclosing } \\
\text { lifetime experience of sexual violence }\end{array}$} \\
\hline & $n=222$ \\
\hline Type of Perpetrators Cited* & $\%$ \\
\hline Fellow student & $51 \%$ \\
\hline Neighbor & $30 \%$ \\
\hline Relative & $11 \%$ \\
\hline Stranger & $10 \%$ \\
\hline Friend & $6 \%$ \\
\hline Other & $3 \%$ \\
\hline Unknown & $1 \%$ \\
\hline
\end{tabular}

*Multiple responses allowed

\section{Receipt of Care}

A large proportion of children who disclosed ever experiencing SV, obtained care (75\%; $n=166)$. The care obtained was primarily in the form of school-based counseling, given that only a low proportion of children required referrals to the GBVRC for comprehensive care. A total of 16 students disclosed experiencing completed rape, and of these, about a third $(n=5)$ were accompanied to the GBVRC for further care. There were various reasons why not all 16 students required comprehensive care, including the fact that the rape incidents were not current, and the students concerned had already received care prior to the screening intervention. However, nearly all of such students (15 out of 16) were willing to receive school-based counseling, and did so.

While the vast majority of children disclosing experiences of lifetime and/or current SV obtained care, not all were willing to receive care immediately. Only $51 \%$ of such students were immediately willing to receive care (and of these, only 16\% were boys). The remaining 49\% declined the available services at first. However, given that the psychologist were present within the schools over a 4-month period, the majority of those who initially declined (97\%) eventually approached the psychologists to request care.

In contrast to the large proportion of children being amenable to obtaining services, hardly any children who disclosed their experience of SV wanted to obtain these services in the company of their female caregivers. Only $4 \%(n=5)$ of those who disclosed ever having experienced SV were willing to do so (all girls), while none of those who disclosed currently experiencing SV were willing to receive care in the company of their female caregivers.

Insights into the reasons for this reticence are provided by the qualitative data:

"I asked her why she didn't tell her mum and she said, "My mom is those tough and strict mothers. I don't know where I will even start with her'."

Fieldnotes, screening, 11 year old girl

"When I asked her why she did not tell her mother, she told me: 'It's hard to tell mum about this. She is very tough and I thought she would beat me'."

Fieldnotes, screening, 13 year old girl
“'My mom is so tough and I don't know where I will start. I have not told her.' I asked her if she could allow me to disclose to her mother in her presence and she said 'yes'. The mom came the following week and she said, 'She can't tell me [such a thing]. I am very tough.' [The mother] was very appreciative..." $\quad$ Fieldnotes, screening, 13 year old girl

The theme of authoritarian parenting permeated children's narratives of preference for care without their female parents or caregivers. Children invariably referred to their mothers' or caregivers' "toughness"-used colloquially to refer to strictness-as a key barrier to parental involvement. 
Culturally, sexuality-related discussion, including SV, between a child and parent are viewed as particularly inappropriate, and a sign of parental laxity. In addition, strict discipline is often perceived as an indication of good parenting, symbolizing a parent's care for her/his children.

Providers of comprehensive care at $\mathrm{KNH}$ also observed these parenting predicaments, intimating that fathers acknowledged confronting parenting challenges as well:

"We noted, and the fathers also noted [during a parent dialogue], that there is a gap in the way they relate with their children. There is a gap in parenting. The way children are parented, there is a very big gap. We also noted that even the way the parents relate with each other, there is a very big gap. So, we [wonder] whether it is parenting skills that these parents require." Group interview, GBVRC providers

\title{
Perceived Appropriateness of the Intervention among School Personnel
}

The acceptability of the intervention resonated in interviews with school personnel who called for expanding the screening intervention either to additional age groups, or to more children in general:

\begin{abstract}
"I think all schools should have [the screening intervention] because, whether we accept it or not, child sexual abuse has become very common...it is here with us, and the sooner we accept that...the better it will be for the children and our society. So, for me, I feel it should be all over the country." Interview, guidance and counseling teacher 1, school B
\end{abstract}

"Probably in [the] future-you know, they were looking at children from class 6 to 8 . There are other children who are vulnerable...I think we need the screening to involve almost the entire school...Because you find a child in class 3 has been raped, so when we skip them, we are missing on something."

Interview, head teacher, school B

In addition, teachers acknowledged that their lack of capacity to handle screening, and the fact that their role as disciplinarians conflicted with the kind of persona required for effective screening. Consequently, teachers intimated that, unlike external parties and individuals with training in psychological counseling, they were not well-positioned to conduct screening. These perceptions reveal the high degree of suitability school personnel assign to this screening intervention:

"At our school...many abuses happen and at times we know...But being teachers, we cannot go beyond-there are some levels we cannot go beyond. Maybe a child will not report, but in the class, you will find the way the child is [acting], there must be something wrong with the child. Trying to inquire, the child might not open up to explain to you where the problem is...So, bringing an intervention like this one here will be a great help to our children. We value them very much and we would really like them to have some counseling help. As teachers here, having the teaching and other things to do, we may not go beyond."

Interview, guidance and counseling teacher 1, school A

"I think [the intervention] is good because it is giving them [children] an opportunity to interact with strangers, people they don't know. You know as a teacher, it is very difficult for a girl to open up, because, for one, I play two roles. As much as I want to guide and counsel, sometimes it can't work because I also have to instill discipline. So, they try to kind of run away. They could be having issues but, "How will I [disclose when] this is the same teacher who punishes me when I don't finish my homework?' But dealing with faces you have never met and they actually want to get the same information, I think it is a pretty [good] thing."

Interview, guidance and counseling teacher 2, school A

"[The intervention] has made me realize that we are really not doing what we are meant to do, per se. We are not giving these children the kind of time that they need to be able to voice their issues, and sometimes we assume too much. I have come to that realization...many a times, when children have behavior problems, they are really not behavior problems. They come from certain issues that are unresolved. And I think if we had been doing our job, per se, we would be able to identify these children, and to actually bring help to them, so that they are able to cope with this. So, I have come to that realization that what we are doing is not enough and we really need to step up."

Interview, guidance and counseling teacher 1, school B 
Each intervention component was viewed as critical as well as responding appropriately to needs along the school-home continuum:

"Even the attendance of the parents in those two [dialogues]...it was the highest so far. I think the fathers who came yesterday were over 60 . The parents who came here for the first meeting were over 200-and also the fact that they were able to be given a meal, is attractive enough for them to say that if we are going to have a meal, let's go and hear what they have to say. And at the end of it, it's not the meal that is important, it's the information which they received. You know, even in the school, we can teach about sexuality, but at home, are they aware? So, now, we are walking with the child, the parent, and the school, which is quite encouraging, unlike other programs where you impart the information to the child and it ends there. But here, you have everyone on board."

Interview, head teacher, school B

\section{Perceived Demand for the Intervention in the Wider Community}

The intervention targeted children (along with their parents or caregivers) in school and health facility settings; however, in the course of implementation, indirect beneficiaries also demonstrated demand for the intervention and their communities' need for it. The implementation process within schools appeared to have a ripple effect on the wider community, compelling children, parents, and school personnel to link others (outside of the study context) to the intervention.

"The children we were screening were saying, 'Me, I have not been sexually abused, but my friend from another school was raped. So, can I tell my friend to come here?' So, you see, we are passing the information, but we are limited, so this should be done in more schools and in the community also."

\section{Group interview, school psychologists}

"After the [parent dialogue]...one of the teachers also pulled us aside and asked if we could help one of her former students. The young man had been volunteering at the school during the term and he asked her what we were doing at the school. She explained to him that we were there to screen children for sexual abuse. He then asked her if we could help him, even though he was not one of the students. [He was a sexual violence victim and did get help]."

Fieldnotes, parent dialogue, school A

"The parent said that he had attended the first parent dialogue and what we discussed during the meeting had touched him greatly and had opened his eyes to what was going on in his community. He said that he was greatly disturbed by what he had noticed in his neighborhood. One of the teachers who lives in his neighborhood had recently married a girl in Form 3 and the girl was now pregnant. He said that he tried talking to the girl's mother, trying to convince her to seek help. He said that he mentioned [his child's school] had a program and that they could help her. This parent said that he has tried his best to convince the mother of the girl to seek help and that he had finally convinced her to get help. He wanted to know if there was anything we could do." Fieldnotes, parent dialogue, school B

\section{Satisfaction with the Screening Intervention among Children}

Importantly for this study, children were particularly satisfied with the screening initiative. Their narratives of satisfaction principally focused on their improved abilities to communicate with their parents about their experiences of SV, as a result of both the screening (which unearthed their SV experiences) and the parent dialogues (which prepared parents to discuss such a sensitive subject). Even children for whom the intervention did not necessarily help improve parent-child communication barriers expressed satisfaction with their sense of empowerment after the intervention:

"The girl was very happy because she got courage to disclose to her mom how this man has been trying to rape her and the mother really protected her by confronting the man. The man apologized, saying he didn't mean that, and her dad also went to warn him. 'I think you people helped our parents a lot by telling them to talk to us, because this is something I was not going to tell my mom, who is very strict. We are very free nowadays and we talk so much about sex. You have helped us a lot."

Fieldnotes, screening, 11 year old girl 
"The girl came to tell me, she disclosed to her mom about this neighbor's behavior of wanting to rape her, and the man got into trouble. 'My dad took him to the chief and the man was to be taken to the police. He begged and he was very shocked because he didn't know I would ever tell anybody. After that, I saw him once and I have never seen him again. Thank you very much for helping me tell my parents, who supported me so much'."

Fieldnotes, screening, 12 year old girl

"This has been the hardest thing to do. I was not able to tell my mom, but my uncle came and he was trying to touch me and I shouted and told him, "If you try to touch me again, I am going to report you to my mom.' He was so scared because I have never talked to him. He begged me not to tell anybody and said he will never try it again. I told myself this is the best thing that has happened to me-that courage to tell him to his face.'

Fieldnotes, screening, 13 year old girl

"I told my mother how this neighbor used to force me to [look at] pictures of people having sex, especially the 'boys-to-boys,' or 'men-to-men' kind. My mother and other people in our neighborhood approached him and took him to the Chief's office. Some of my friends in the neighborhood also confessed that the same man had had sex with them. My father was equally happy that I told my mother about it and encouraged me never to keep quiet should someone do anything like that to me. He looked at me calmly and firmly told me that they are my parents and I shouldn't fear them. Sincerely speaking, I used to fear them, but since that time, I am very free with them. Thank you."

Fieldnotes, screening, 13 year old boy

\section{Perceived Positive Effects on Organization}

Perhaps due to the intervention's relatively short duration, narratives of its perceived effects (whether positive or negative) on the schools or hospital were not pervasive within the data. In the school sites, however, positive perceptions among school personnel of students' increased confidence was a recurring theme. Some school staff believed children's participation in the screening intervention, with its emphasis on fostering openness, communication, and disclosure, seemed to enhance their confidence in their schools' regard for them, evinced by proactive communications with their teachers, and improved academic endeavors:

"But so far, I think it has given children confidence that on this earth, there is somebody who cares and there is somebody who [wants] to know how this child lives. So, the effect which I can think is taking place now [involves] making children walk with confidence, making children be happy and making children recognize that somebody cares somewhere for my life." Interview, head teacher, school A

"Generally, what I have seen is that-like in my class now-I have seen [students] trying to come closer to the teacher now. They are a bit free with me now, even to come and tell me, 'Teacher, this is what I feel'...But now, like, all of them, they are able to present their cases to the teacher without any fear. At least that one I have seen from my class, because those are the ones that I interact with mostly."

Interview, guidance and counseling teacher 1, school A

"And, you know, once children have opened up, they have been assisted, it may also translate to better performance, because when you solve a problem, it is not disturbing you anymore. I believe it is also a way of helping our children even to perform [academically]. Then, number two, they have the confidence in themselves to report-even if not to you people, then maybe to a parent or even a teacher that they choose to confide in...And even from the side of the teachers, there are some positive comments-that the children have the confidenceespecially those classes where they were taking the [screening] exercise from class 6 to 8 ....that there is some positive impact on the children...even response in class...there is some confidence among the learners, [evidenced] by being more responsive in class." Interview, head teacher, school B 


\section{Fit within Organizational Culture}

Evidence of the extent to which the screening intervention fit within the organizational cultures of the study sites featured in the qualitative data from schools, in particular. This is unsurprising, as hospitals habitually perform and manage various kinds of screening protocols, while on-site screening is a relatively novel activity for schools.

During screening times in the school sites, psychologists worked closely with guidance and counseling teachers to ensure children were systematically directed to the screening room. In general, this added responsibility was positively accepted by guidance and counseling teachers, and some managed it without any inconvenience:

"In terms of time, it has never affected my time. Because what [students] do, they come here during break time. They come during lunch hour. They come at 3:10 [pm]. These hours, the children are not in class. So, there is no teacher who can claim that the lessons are missed. There is no child who can claim that the lessons are missed. The children are learning normally. So, it has been positive, I can say; it has not affected me negatively. It has not affected my program. My lesson planning-whatever I have planned for the lesson-I do it, and when they call me [to begin the screening exercise], whatever I do is just to prepare the [screening] room prior...So it has not affected the operations of the classes and the teaching exercise." Interview, guidance and counseling teacher 2, school B

The arrangement posed challenges for others, however, pointing to some level of incongruity between the screening intervention and the schools' organizational cultures:

“We [guidance and counseling teachers] actually, like, don't have break time because you have to guide the children [to the screening room] during break time...In the evening, it is the same thing. Personally, my classes end at 3:10 [pm]. My children go home at 3:10. But now, I cannot go away if the psychologists are here, because they are [my responsibility]. I have to stay until the time when they are done. Traditionally, I go home at 3:10, but now, I have to stay until 4:10 or 4:30 when they leave. And in the event that I have to go, then I have to ensure that there is somebody else to take charge and ensure that [the intervention] goes on. So, there is a bit of that discomfort, but nothing extreme that I can talk of."

Interview, guidance and counseling teacher, school B

“Just an example: Sometimes...it is lunch time and I know the group that [screening is about to start]. I and [the other Guidance and Counseling teacher], we supervise the lunch very fast. We forego our lunch that time, then supervise the lunch for those children who are going so that they can go there very fast." Interview, guidance and counseling teacher 1, school A

The issue of time featured in respondents' narratives in other ways. For instance, the limited time available for screening during school days was raised as a concern:

"O.K., what I can say is-the timing, the timing is very short-because it is only 30 minutes break time, another maybe 30 minutes...in the evening, you know these children are in class...So, I was thinking; if it could be done over the holidays, and also, we could arrange for different classes to come over the weekend, so that every weekend, they can have like a session of two hours. Then this, I think, would have been better, yeah." Interview, head teacher, school A

As intimated below, teachers were accustomed to having the luxury of extra time (beyond the end of their actual class time) to finish up their lessons. The screening intervention occasionally interfered with this:

"I cannot say that [the intervention] has disorganized me in any way because it is part of what I am doing...But you see...sometimes it is challenging because some teachers will be like, 'Give me five [more] minutes.' And you see, like, those five minutes-the others are also waiting [to be screened]...I don't want to make the teacher to feel as if I am interfering with their work. At the same time, I also want to make sure that the kids have gone down to the [screening room]...But otherwise it is okay; we understand. I don't blame the teacher because he or she also wants to finish whatever he wants to do..."

Interview, guidance and counseling teacher 2, school A 


\section{Hospital Context}

\section{Actual Use of the Intervention among Children}

Despite the health workers' strike at KNH throughout the study period, findings from the screening intervention in this health facility context mirrored those from the school settings.

A total of 41 children ages 11-17 presented for care at the hospital's Casualty Department during this period. All 41 children were willing to be screened, and all female parents accompanying the children for care were willing for their children to be screened privately. Of the 41 children, $46 \%(n=19)$ were female and 54\% $(n=22)$ were male. Among those screened, 10\% $(n=4)$ disclosed ever having experienced SV. One out the 4 that disclosed this - a boy - was currently experiencing SV. Almost all screened children who disclosed ever experiencing SV (3 out of 4) pinpointed a fellow student as being the perpetrator. Insights into perpetration by fellow students are provided by the case of the only child who disclosed current SV experience:

“[The child] was brought in by the mother due to school expulsion due to stealing ksh 3,000 [US \$30]. During [the] counseling session, he revealed that he stole so that he would be expelled and go to another school since he didn't have any other way of explaining to his mother about the abuse. Has been sodomized by several students several times. Was [asked] whether the mother can be informed and he accepted. Referred to be seen by doctor...When the mother is available, to be taken to [the GBVRC] for follow up counseling."

Fieldnotes, screening, 16 year old boy

The sensitive, detailed information disclosed by this child to a screening psychologist further demonstrates children's high comfort level in regard to the screening process. This is particularly the case, given that the child in question had not informed his accompanying parent about his experience of SV, but was willing to disclose this to a provider when screened.

Nearly all those who disclosed ever having experienced SV (3 out of 4) immediately accepted care, were willing to receive care in the company of their female caregiver, were referred to the GBVRC for further care, and did receive care following the referral.

\section{Perceived Appropriateness of the Intervention among Parents and Hospital Personnel}

Universal permission by female parents at KNH for their children's SV screening indicates the degree of parental approval of this intervention's appropriateness. Similar to school personnel, hospital staff advocated for expansion of the screening intervention, expressing their belief in the appropriateness of routine screening of children, and in the intervention's approach in conducting parent dialogues. Hospital staff narratives tend to focus on how the intervention could have been modified to prepare for expansion in a subsequent phase, with suggestions, for example, for expanding the intervention to strategic clinics at $\mathrm{KNH}$ :

"But we have [children aged] 11 to 12 years in the medical wards. Then, we have ward 4A, which is the surgical ward. These kids are going there with other injuries, but we can screen them for that, and I am double sure we will get kids [identify child survivors] there. If we take it to [the] pediatric clinic, you can also get [survivors aged] 11 to 12 years...Because we were looking at it sometime back while discussing sexual abuse and we were saying that even the ones going to the wards under 11 years should be screened..."

\section{Group interview, KNH psychologists}

Hospital personnel seconded to the study's primary schools also discussed the value of routine screening, emphasizing that disclosure often takes time, and that screening more than once afforded child survivors the time necessary to feel comfortable with disclosing their SV experiences:

"I think they [screened children] really liked it...They would come back on their own now, for counseling. They would come to ask questions. They would come and say, 'The first time you 
asked me this question, I told you 'no.' But this is the truth: It happened.' You know, you have already built trust with this child and this child will be bringing themselves for counseling, without [your] even calling them. So, it shows they appreciate counseling."

\section{Group interview, school psychologists}

As further indication of the perceived appropriateness of the intervention, hospital staff emphasized the impact of the parent dialogues, which they believe fostered meaningful parental participation in the intervention, and revealed parents' own need for psychosocial support:

“Like, for example during the dialogue meeting-the Fathers' Day that we had, and the other meeting [mixed-gender parent dialogue] that we had...I know you didn't mix them [male and female parents] at all [during Father's Days], but you could see even parents want to come back after that. So, I was imagining that if these psychologists had more time to be available in the schools-because I saw them [parents] wanting to ask many questions from experts. So, I was wondering that if such kind of a provision is there, so that they know that [psycho-social support professionals] are available for them."

Group interview, GBVRC providers

\section{LIMITATIONS}

This study had a number of limitations. It relied on a sample of children and parents who consented to participate in the screening intervention, without gathering in-depth information on those who did not consent to participate. While consenting parents and children are a requirement for this intervention (from an operational as well as ethical perspective, both within and beyond the confines of a study), further insight into the barriers to participation would have been valuable for enhancing the intervention.

Parental permission was required for children's participation in SV screening, and even though some children who disclosed SV identified relatives (including parents) as their perpetrators, the parental permission requirement might have posed a barrier for other children in similar situations. It is plausible that parents perpetrating SV with their own children were less likely to participate in the intervention, (i.e., the parent dialogues), and to grant permission for their children to be screened for SV. The proportion of children disclosing relatives as perpetrators was also relatively low compared to the proportion identifying fellow students as perpetrators.

Although this study focused on the feasibility (rather than effectiveness) of SV screening, the screening tool employed has not been subjected to randomized controlled trials, which could provide more rigorous evidence about its effectiveness in identifying child survivors and linking them to care. . 


\section{DISCUSSION AND CONCLUSION}

This study employed eight outcomes of interest identified by Bowen and colleagues (2009) to determine the feasibility of screening children for sexual violence in school and health facility settings. All feasibility outcomes (8 out of 8 ) were met in the school and health facility sites combined.

Findings from this screening study confirm that if we ask children about their experiences of SV, they will tell us about these experiences despite the sensitivity of the subject. Furthermore, with the meaningful involvement of children's parents/caregivers, the latter are bound to be supportive of screening, and to serve as important supporters of their children as they negotiate traumatic events. Providers either implementing or supporting this intervention (whether in schools or health facilities) found it so suitable that many want to include it in their own practice, or to promote its integration within their own work cultures, with some form of external support for implementation.

This study has been deliberate in avoiding the term "prevalence" to quantify children's experiences of SV. Instead, the term "disclosure" has been used liberally in recognition of the fact that some children simply may not have been ready to disclose their experiences of SV during the intervention period. Children in the two schools were screened twice, and these study results are based on the second round of screening at the schools, along with the sole round of screening at the hospital. By the second round of screening in schools, children were more likely to disclose SV, as they were more comfortable with the screening psychologists. It is plausible, with more time and further screening rounds, that a greater number of disclosures could have been registered.

The importance of adequate implementation time for this sort of intervention is further underscored by the fact that a considerable proportion of children in the school sites who had experienced SV (mainly boys) were unwilling to receive care right away. However, with time available to offer care more than once (and for children to get used to the idea of the intervention), most of such children did eventually see the need for care, and did receive the care they needed.

Interestingly, children screened in school contexts were less willing than those screened in the hospital setting to seek care immediately, and to do so in the company of their female parent or caregiver. Although the sample size of children screened at the hospital was much smaller, this finding suggests that screening interventions for children must be customized for individual contexts. It is possible that in settings where children are accustomed to functioning more independently (such as schools), less parental involvement is required for this sort of intervention, compared to settings such as hospitals, where children are bound to rely more on parents and caregivers for support and guidance. Related to this is the need for parenting interventions to accompany child-centered SV screening interventions. While parent dialogues were employed as part of this screening intervention, multiple means of engaging parents and caregivers should be explored to resolve parent-child communication barriers, ensure that parents and caregivers are properly informed about such interventions in advance, and to enlist parents as proactive champions against SV in the lives of their children and in their communities.

Children who disclosed more than one type of SV experience concurrently almost invariably mentioned genital touching as an element of that experience. This finding stresses the importance of "good touch/bad touch" interventions with young children. Genital touching often serves not only as an initiating point for SV, but also as a precursor to other forms, and interventions that mitigate SV as early as possible in the process of violation, and where possible, before it begins, are critically important.

Given the high proportion of child survivors identifying fellow students as SV perpetrators, concerted action is needed to prevent SVAC by targeting children themselves as potential perpetrators. Interventions addressing this stark reality could include education for children around consent, healthy relationships, and healthy sexuality, for example.

Despite the positive results of this study, we do not recommend establishing SV screening interventions for children when resources required for a comprehensive response are limited or unavailable. There 
are, however, ways in which the intervention described in this report could be adapted for wider use in low-resource settings. While staffing schools with trained psychologists might require resource commitments that are impossible in many areas, having government psychologists, trauma counselors, or social workers 'adopt' a number of schools and pay periodic visits for the purpose of screening and response might be one means of adapting this intervention. In the words of a school staff member:

“After screening [the children], you don't need to end there. It should be something continuous because now when you leave, you don't leave them in a vacuum, because [SV] cases are on the rise. Don't say that you are leaving and then when another case comes up, there is nobody, apart from a normal teacher. The psychologists should be there continuously because it is something new, but very vital. Even if they are not stationed here throughout, they should be somewhere you can call if there is an issue, and then you come to our rescue." Interview, deputy head teacher, school A

Strong links to comprehensive care, such as one-stop response centers for SGBV, would be a critical component of any SV screening intervention, and the organizational culture of any potential screening site must be considered. Any new intervention will require at least some alterations in existing organizational cultures, but the study results suggest that such alterations will most likely be moderate in school settings, and very limited in health facility settings.

In conclusion, findings from this study indicate that screening for SVAC is feasible in both school and health facility settings, and that such screening holds potential for expanding child survivors' access to care. 


\section{REFERENCES}

Bowen, D.J. et al. 2009. How we design feasibility studies. Am J Prevent Med 36(5): 452-457.

Creswell, J.W., V.L. Plano Clark, M. Gutmann, W. Hanson. 2003. Advanced mixed methods research designs. In A. Tashakkori \& C. Teddlie (eds.), Handbook of mixed methods in social and behavioral research. Thousand Oaks, CA: Sage.

Emerson, R.M., R.I. Fretz, L.L. Shaw. 1995. Writing ethnographic fieldnotes. Chicago: University of Chicago Press.

Kaitelidou, D., C. Economou, P. Galanis, O. Konstantakopoulou, O. Siskou, S. Domente, D. de Boer, W.G. Boerma, P.P. Groenewegen. 2019. Development and validation of measurement tools for user experience evaluation surveys in the public primary healthcare facilities in Greece: a mixed methods study. BMC Family Practice 20: 49.

MacMillan, H.L., C.N. Wathen, E. Jamieson et al. 2009. Screening for intimate partner violence in health care settings: A randomized trial. JAMA 302(5): 493-501.

Ministry of Labour and Social Protection of Kenya, Department of Children's Services. 2019. Violence against Children in Kenya: Findings from a National Survey, 2019. Nairobi, Kenya.

Myers. M.D., M. Newman. 2007. The qualitative interview in IS research: Examining the craft. Info and Org 17: 2-26.

www.pm.Ith.se/fileadmin/_migrated/content_uploads/5._Qual_Interview_Texto_Leitura_Atividade 2.pdf

Patton, M.Q. 2003. Qualitative evaluation checklist. http://wmich.edu/evaluation/checklists.

Population Council. 2016. Fostering a multisectoral response to violence against children in East and Southern Africa. Learning updates from Kenya, Brief 4. The Africa Regional SGBV Network Learning Brief Series. Population Council: Nairobi, Kenya. www.popcouncil.org/uploads/pdfs/2016RH_LearningBrief4_KenyaKNH.pdf.

Sanjek, R. (ed.). 1990. Fieldnotes: The makings of anthropology, Ithaca, Cornell University Press.

Shallcross, R., J.M. Dickson, D. Nunns, K. Taylor, G. Kiemle. 2019. Women's experiences of vulvodynia: an interpretive phenomenological analysis of the journey toward diagnosis. Archive Sex Behav 48: 961-974.

Smith, J.A., P. Flowers, M. Larkin. 2009. Interpretative phenomenological analysis: theory, method and research. London: Sage.

Undie, C., M.C. Maternowska, M. Mak'anyengo, I. Askew. 2013. Feasibility of routine screening for intimate partner violence in public health care settings in Kenya. Nairobi: Population Council. www.popcouncil.org/uploads/pdfs/2013RH IPV-FeasibilityReport.pdf

Undie, C., M.C. Maternowska, M. Mak'anyengo, I. Askew. 2016. Is routine screening for intimate partner violence feasible in public health care settings in Kenya? J Interpers Violence 31(2): 282301.

Undie, C., S. Mullick, I. Askew. 2013. The missing 'C': Sexual violence against children in sub-Saharan Africa. Research Watch, UNICEF.

WHO. 2016. INSPIRE: Seven strategies for ending violence against children Executive Summary. WHO: Geneva.

WHO. 2019. Violence against children: Key facts. www.who.int/news-room/factsheets/detail/violence-against-children. 


\section{APPENDICES}

\section{Appendix A: Screening Tool Administered in the School Sites}

\section{SCREENING TOOL: SEXUAL VIOLENCE AGAINST CHILDREN}

\section{NOTES FOR PSYCHOLOGIST:}

1. This tool is to be used during school recess and any free periods in Grades 6-8.

2. This tool is to be used only with students meeting all of the following criteria at [Name of School]:

Those in Grades 6-8

Those who have a record of parental permission on file

Please consult your register for the list of students meeting these criteria.

3. Using this screening tool could pose psychological risks for students who have experienced sexual abuse. Be alert to signs of distress during the screening process. Be prepared to offer immediate counseling, if deemed necessary and desired by the student. Further instructions may be found at the end of this screening tool.

NAME OF STUDENT: CLASS:

\section{Introduction}

Hello, [Name of Student]. How are you today? My name is [Name of Psychologist].

Please have a seat. Thank you for stopping by my office today. I'm not going to take too much of your time.

Now, remember how we've been having assemblies where we talk about 'good touches' and 'bad touches,' and 'sexual abuse,' and about how students should let someone know if this is happening to them so they can get help? And you may also remember that we always mention that we want to do something about 'sexual abuse' to help any students in school who may be going through this. Do you remember hearing about this? [If not, provide an overview.]

Okay, great. Now, we are asking students at this school a few questions just to see if there is anyone that needs help. If I ask you a question that you do not want to answer, I want you to just hold up this red card, okay? If you do that, I will just move on to the next question.

Do I have your permission to continue?

YES NO __ (if 'NO,' end the screening exercise)

Now, we've talked a lot about 'sexual abuse' during school assemblies. Can you tell me what 'sexual abuse' means? [Offer praise for the student's understanding of the term. Fill in any gaps, if necessary.] 
Now, if you don't feel comfortable answering 'yes' or 'no' to this next question, you can write down your answer for me instead, okay?

Question 1: Have you ever been sexually abused?

YES _ _ N _ _ (if 'NO,' skip to Closing 1)

I'm so sorry to hear that. We talked about what 'sexual abuse' means, and the different kinds of sexual abuse. If you don't feel comfortable answering this question out loud, you can write down your answer for me, or show me what you mean using these two dolls.

Question 2: What kind of sexual abuse has happened to you?

Insert description here. Probe to determine type of sexual abuse, e.g.: rape, attempted rape, touching of private parts, attempted touching of private parts, being forced to touch the private parts of someone else, or to perform any kind of sexual act, being forced to watch pornographic movies, etc.

If you don't feel comfortable answering this question out loud, you can write down your answer for me.

Question 3: Who were you sexually abused by?

Stranger _ Relative (specify) _ Neighbor _ _ Fellow Student __ Other (specify)

Question 4: When did the sexual abuse happen?

YEAR _ MONTH__ DON'T REMEMBER

If you don't feel comfortable answering this question out loud, you can write down your answer for me, or show me what you mean using these two dolls.

Question 6: What kind of sexual abuse is happening right now?

Insert description here. Probe to determine type of sexual abuse, e.g.: rape, attempted rape, touching of private parts, attempted touching of private parts, being forced to touch the private parts of someone else, or to perform any kind of sexual act, etc.

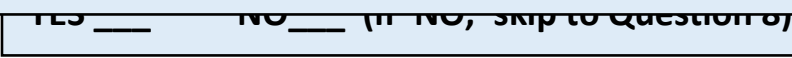

If you don't feel comfortable answering this question out loud, you can write down your answer for me. 
Question 7: Whom are you being sexually abused by?

Stranger _ Relative (specify) _ Neighbor _ _ Fellow Student __ Other (specify) _

Question 8: It would be good to get some help to make sure you are healthy. Would you like to get some help?

YES _ _ NO_ _ (if 'NO,' skip to Closing 2 2)

I'm sorry to hear about what you've gone through. I want you to know that there are different kinds of help we can offer. We can start by having you talk to someone about what is going on so that we can find out the kinds of help that you need.

Question 9: Would you like your mother/female caregiver to be with you when you get help, or would you like to be alone?

ALONE _ _ WITH MOTHER/FEMALE CAREGIVER

(When done with this question, skip to Closing $\underline{2}$ )

Closing 1 (for those who have not experienced sexual abuse)

I want you to know that it was brave of you to come in and talk about sexual abuse. I'm happy that you are not going through this. I will call you in a number of times over the next few months just to make sure everything is going well with you. If any kind of sexual abuse ever happens to you, please do not keep quiet about it. Feel free to stop by and see me to talk about it, or make sure you tell someone that you trust. Many children going through sexual abuse do not know who to tell or that help is available. I just want you to know that there is help, in case you ever need it. Also, if any other student at this school tells you that they are going through sexual abuse, I would like to ask you to tell them not to be afraid, but to come talk to me. Do you have any questions for me before you leave?

\section{Closing $\mathbf{2}$ (for those who have experienced sexual abuse)}

I want you to know that you've done a very brave thing today by telling someone about what you're going through. You have not done anything wrong or 'bad', and you are not to blame for what has happened/is happening. Now that we know you need some help, we are going to do everything we can to make sure that you get it.

There are many other children who are going through the same thing, but they don't know who to tell and they don't know that help is available. If any other student at this school tells you that they are going through sexual abuse, I would like to ask you to tell them not to be afraid, but to come talk to me. Do you have any questions for me? 


\section{NOTES FOR PSYCHOLOGIST:}

Students disclosing sexual abuse have already been asked if they would like to talk further and get help along with their caregiver.

For those preferring to get help along WITH their caregiver: Initiate the referral process: contact the caregiver via phone or home visit. Advise caregiver of the situation and of available services. Schedule a GBVRC appointment, and inform the caregiver of the date and time. Ensure that the caregiver and student are accompanied on this appointment by a psychologist trained under this intervention.

For those preferring to get help WITHOUT their caregiver: Provide an initial counseling session on-site. Based on this session, devise a counseling plan for the student which will take place at school. It is important to take the students' opinions about their home situation seriously. If a student is of the opinion that involving their caregiver in this situation would be risky or undesirable, do not try to convince them otherwise. Rather, proceed to provide on- 


\section{Appendix B: Screening Tool Administered in the Hospital Site}

\section{SCREENING TOOL: SEXUAL VIOLENCE AGAINST CHILDREN}

\section{NOTES FOR TRAINED PROVIDER:}

1. This tool is to be used for all children presenting at the KNH Casualty Department, ages 11-17.

2. This tool is to be used only with children meeting all of the following criteria at the Casualty Department:

a) Those aged 11-17

b) Those presenting for care alone or with a female caregiver only

c) Those who are not too ill to be screened, AND

d) Those whose female caregivers have given oral permission for them to be screened

3. Using this screening tool could pose psychological risks for children who have experienced sexual abuse. Be alert to signs of distress during the screening process. Be prepared to offer immediate counseling and/or to refer the child to the GBVRC, if deemed necessary and desired by the child. Further instructions may be found at the end of this screening tool.

NAME OF CHILD:

SEX:

AGE:

DATE:

\section{Introduction}

Hello, [Name of Child]. How are you today? My name is [Name of Provider] and I work here as a [Position/Role].

Please have a seat. I'm not going to take too much of your time.

We have started asking children at this hospital a few questions just to see if there is anyone that needs help. If I ask you a question that you do not want to answer, I want you to just hold up this red card, okay? If you do that, I will just move on to the next question.

We have realized that some children experience 'sexual abuse' and do not know where to seek help. When someone touches a child in his/her private areas, or tries to have sex with a child, or forces a child do anything sexual that makes the child feel uncomfortable (e.g., touching or watching pornographic movies), it is 'sexual abuse.' Sexual abuse can lead to many health problems. This is why we are trying to identify children who might be experiencing this, so that we can get them get the care they need right here at the hospital.

Do you understand what I have said?

Do you have any questions for me about what I have said?

Question 1: Have you ever been sexually abused?

YES __ N N _ _ (if 'NO,' skip to Closing 1)

I'm so sorry to hear that. We talked about what 'sexual abuse' means, and some of the kinds of sexual abuse. If you don't feel comfortable answering this question out loud, you can write down your answer for me, or show me what you mean using these two dolls. 
Question 2: What kind of sexual abuse has happened to you?

Insert description here. Probe to determine type of sexual abuse, e.g.: rape, attempted rape, touching of private parts, attempted touching of private parts, being forced to touch the private parts of someone else, or to perform any kind of sexual act, being forced to watch pornographic movies, etc.

If you don't feel comfortable answering this question out loud, you can write down your answer for me.

Question 3: Who were you sexually abused by?

Stranger _ Relative (specify) _ Neighbor _ _ Fellow Student __ Other (specify)

Question 5: Are you being sexually abused right now?

YES _ _ N _ _ _ (if 'NO,' skip to Question 8)

If you don't feel comfortable answering this question out loud, you can write down your answer for me, or show me what you mean using these two dolls.

\section{Question 6: What kind of sexual abuse is happening right now?}

Insert description here. Probe to determine type of sexual abuse, e.g.: rape, attempted rape, touching of private parts, attempted touching of private parts, being forced to touch the private parts of someone else, or to perform any kind of sexual act, being forced to watch pornographic movies, etc.

If you don't feel comfortable answering this question out loud, you can write down your answer for me.

Question 7: Whom are you being sexually abused by?

Stranger _ Relative (specify) _ Neighbor _ F Fellow Student _ Other (specify)

I'm sorry to hear about what you've gone through. I want you to know that there are different kinds of help we can offer. We can start by having you talk to someone about what is going on so that we can find out the kinds of help that you need. 
Question 8: It would be good to get some help to make sure you are healthy. Would you like to get some help?

YES _ _ NO_ _ (if 'NO,' skip to Closing 2

Question 9: Would you like your mother/female caregiver to be with you when you get help, or would you like to be alone?

ALONE _ _ WITH MOTHER/FEMALE CAREGIVER__

(When done with this question, skip to Closing $\underline{2}$ )

(When done with this question, skip to Closing 2)

\section{Closing 1 (for those who have not experienced sexual abuse)}

I want you to know that it was brave of you to talk about sexual abuse. I'm happy that you are not going through this. If any kind of sexual abuse ever happens to you, please do not keep quiet, but tell somebody you trust. Also know that you can get help from us here at KNH. Many children going through sexual abuse do not know who to tell or that help is available. I just want you to know that there is help, in case you ever need it. Also, if any other child you know tells you that they are going through sexual abuse, I would like to ask you to tell them not to be afraid, but to try to get help at Kenyatta National Hospital.

\section{Closing 2 (for those who have experienced sexual abuse)}

I want you to know that you've done a very brave thing today by telling someone about what you're going through. You have not done anything wrong or 'bad', and you are not to blame for what has happened/is happening. Now that we know you need some help, we are going to do everything we can to make sure that you get it.

There are many other children who are going through the same thing, but they don't know who to tell and they don't know that help is available. If any other child you know tells you that they are going through sexual abuse, I would like to ask you to tell them not to be afraid, but to try to get help at Kenyatta National Hospital.

\section{NOTES FOR TRAINED PROVIDER:}

Children disclosing sexual abuse have already been asked if they would like to talk further and get help along with their caregiver.

For those preferring to get help along WITH their caregiver: Advise the caregiver of the situation and of available services at the GBVRC. Initiate the referral process: contact the child advocate to accompany the child and caregiver to the GBVRC.

For those preferring to get help WITHOUT their caregiver: Initiate the referral process: contact the child advocate to accompany the child to the GBVRC. An initial counseling session on-site (at the Casualty Dept) may also be provided if the trained provider has enough time. 


\section{Appendix C: Parent Permission Form \\ (for parents participating in school-based parent dialogues)}

\section{PARENT PERMISSION FORM}

[DATE]

Dear Parents and Guardians of Pupils in Classes 6-8 at [Name of School]:

Sexual violence against children has become a big problem in schools. Children who have experienced sexual violence need health care and other kinds of support to help them overcome the trauma that it causes. This year, [Name of School] is taking action to ensure that its pupils are able to get the help they need if they do experience this kind of abuse. Parents/guardians also need support when their child experiences abuse, and we want to make sure that parents are included in this process.

We are spending the day with parents/guardians of pupils at [Name of School] to provide more information about how the school will help pupils who have experienced sexual violence. Please feel free to ask any questions you may have during today's meeting.

Sincerely,

Head Teacher, [Name of School]

Please cut off and return the permission form below today, [DATE].<smiles>[SiH2]C1C=C1</smiles>

Pupil's Name

Pupil's Class

Yes, my child has permission to participate in the sexual violence screening exercise at [Name of School] from [Start Date] to [End Date].

Yes, I authorize [Name of School] to take the necessary steps to get care for my child at Kenyatta National Hospital in the event that my child has experienced sexual violence.

No, my child does not have permission to participate in the sexual violence screening exercise at [Name of School] from [Start Date] to [End Date].

Parent's signature Parent's phone number

Date 